\title{
Morfo-anatomia foliar de Ocotea gardneri (Meisn.) Mez (Lauraceae-Lauroideae)
}

\author{
Denise F. Coutinho ${ }^{1,2}$, Maria de Fátima Agra ${ }^{2 *}$,José M. Barbosa-Filho², \\ Ionaldo J.L. Diniz Basílio ${ }^{2}$ \\ ${ }^{1}$ Faculdade de Farmácia, Universidade Federal do Maranhão, Campus do Bacanga, 65040-000, São Luís, MA, \\ Brasil, \\ ${ }^{2}$ Laboratório de Tecnologia Farmacêutica "Delby Fernandes de Medeiros", Universidade Federal da Paraíba, \\ Caixa Postal 5009, 58051-970, João Pessoa-PB, Brasil
}

\begin{abstract}
RESUMO: Ocotea gardneri (Meisn.) Mez é uma espécie arbórea, encontrada no nordeste brasileiro, principalmente nos estados da Paraíba e Pernambuco, conhecida por "louro-branco" e "louro-babão". Neste trabalho realizou-se morfodiagnoses (macroscópica e microscópica) de folhas de $O$. gardneri, com o objetivo de fornecer subsídios à sua caracterização e identificação. Para a morfologia externa, analisaram-se amostras frescas e conservadas em álcool $\left(70^{\circ}\right)$, com auxílio de estereomicroscópio, e observações de campo. Realizaram-se secções transversais em lâminas foliares e pecíolos, e seções paradérmicas nas duas faces de lâminas foliares. Ocotea gardneri possui folhas elípticas a oval-elípticas, margem inteira, levemente ondeada, ápice agudo e base arredondada. A lâmina foliar é hipoestomática com estômatos do tipo paracítico; a epiderme é uniestratificada, com células de paredes retas e espessadas; o mesofilo é isobilateral, aqui referido pela primeira vez para uma espécie de Lauraceae, com células e ductos secretores evidentes e feixes vasculares colaterais envolvidos pela bainha esclerenquimática. Este conjunto de caracteres aliado à morfologia foliar, permitiram o estabelecimento de parâmetros que possibilitarão a caracterização de folhas de Ocotea gardneri em testes de autenticidade, bem como auxiliarão em estudos da taxonomia da espécie estudada.
\end{abstract}

Unitermos: Ocotea gardneri, Lauraceae, Lauroideae, anatomia foliar, farmacobotânica.

\begin{abstract}
Morpho-anatomy of the leaves of Ocotea gardneri (Meisn.) Mez (LauraceaeLauroideae)". Ocotea gardneri (Meisn.) Mez is a tree growing in the Northeast of Brazil and mainly found in the States of Paraiba and Pernambuco. It is known in the region as "louro-branco" and "louro-babão". This work was carried out with morphodiagnosis of leaves of O. gardneri for their characterization and identification. The study of external morphology was carried out with fresh and conserved (alcohol, $70^{\circ}$ ) samples with stereomicroscope complemented by field observations. Anatomical studies were done by transversal sections of leaves (blade and petiole), and paradermic sections in two surfaces of blades. The sections were clarified and stained with astrablue and basic fuchsine. The leaves of $O$. gardneri are elliptic to oval-elliptic, margin entire, slightly wavy, acute at the apex and rounded at the base. The blade leaf is hypostomatic with stomata of the paracytic type; the epidermis is unisseriate with cells of straight and thickened walls; the mesophyll is isobifacial, which is being related here for the first time for Lauraceae, with secretories cells and ducts and collateral vascular bundles involved by sclerenchymatic shealth. These features allowed the establishment of parameters for characterization of the leaves of Ocotea gardneri, as well as to the taxonomic studies on this species.
\end{abstract}

Keywords: Ocotea gardneri, Lauraceae, Lauroideae, leaf anatomy, pharmacobotany.

\section{INTRODUÇÃO}

A família Lauraceae é constituída por aproximadamente 50 gêneros e cerca de 2.500 espécies, com distribuição pantropical, sendo bem representada na América, Ásia, Austrália e Madagascar e pouco expressiva no sul da África (Rohwer, 1993). No Brasil, ocorrem 22 gêneros, frequentemente encontrados em florestas pluviais, restingas e áreas de cerrado (Barroso, 2002).

Lauraceae destaca-se pela sua grande importância econômica, tendo espécies empregadas em indústrias de perfume e cosméticos, materiais de limpeza, alimentos e medicamentos (Marques, 2001).

O gênero Ocotea é um dos maiores da família Lauraceae, possuindo cerca de 300 espécies, encontradas principalmente na região neotropical, porém com algumas espécies na África e Madagascar (Van der Werff, 1991, 2002). Compreendem árvores ou arbustos, com folhas alternas, raramente opostas, flores monoclinas ou diclinas, com fruto do tipo baga sobre cúpula mais ou menos desenvolvida. De acordo com Rohwer (1986), a 


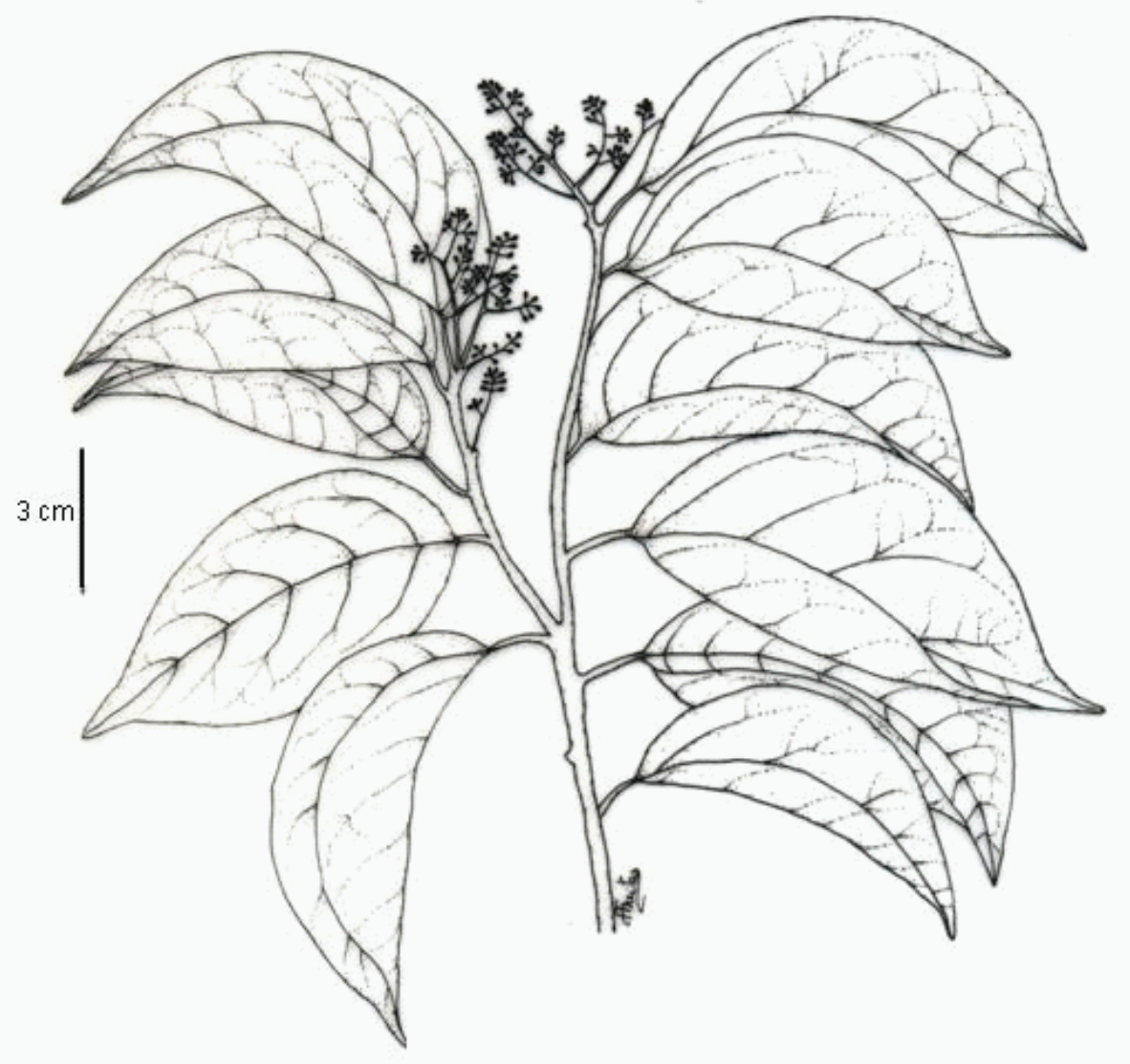

Figura 1. Ocotea gardneri (Agra \& Coutinho 6483). Ramo florido.

delimitação de Ocotea nem sempre é fácil, principalmente em relação a Cinnamomum e Nectandra.

Quimicamente, o gênero caracteriza-se por apresentar em sua composição metabólitos secundários, como alcalóides isoquinolínicos, lignanas e óleos essenciais (Budel; Farago, 2004; Dias 2003; Barbosa et al., 1999). Dentre as atividades farmacológicas já encontradas em algumas espécies de Ocotea, destacamse como antioxidante (Bruni et al., 2004), antibacteriana (Souza et al., 2004), antifúngica (Souza et al., 2004), antiinflamatória (Zschocke, et al., 2000a,b), antialérgica (Serra et al., 1997), depressora do SNC (Morais et al., 1998), relaxante muscular (Ribeiro et al., 2003), hipotensora (Dias et al., 2004), e antagonista do PAF (Faria-Neto et al., 1995a,b), entre outras.

Ocotea gardneri (Meisn.) Mez é uma espécie exclusiva da flora brasileira, somente encontrada na região Nordeste, registrada para os Estados da Paraíba, Rio Grande do Norte, Pernambuco e Bahia, onde é conhecida como "Louro-branco" ou "Louro-babão". Informações sobre suas atividades farmacológicas e seus constituintes químicos ainda são desconhecidos.

Lauraceae é um dos grupos de Angiospermas de maior dificuldade para a caracterização de suas espécies, principalmente pela significativa uniformidade morfológica existente entre os táxons (Castiglioni, 1951). Entretanto, estudos anatômicos de folhas, frutos e lenhos de espécies de Lauraceae têm apoiado os estudos taxonômicos do grupo, atuando como uma ferramenta adicional na identificação de táxons, como são evidentes nos trabalhos de Gutierrez e Oliveira (1987/1989), Santos e Oliveira (1988, 1995), Souza e Moscheta (2000), Marques (2001), Oliveira, Callado e Marquete (2001) e Farago et al. (2005).

Apesar da ausência de estudos científicos prévios para Ocotea gardneri, os estudos químicos que estão sendo realizados com caule e folhas desta espécie têm apresentado resultados bastante promissores (comunicação pessoal). Neste trabalho realizou-se um estudo morfo-anatômico de folhas de Ocotea gardneri com morfodiagnoses macroscópicas e microscópicas, com o objetivo de preencher uma lacuna existente relacionada à morfo-anatomia desta espécie que forneçam, subsídios à sua caracterização e taxonomia.

\section{MATERIAL E MÉTODOS}

\section{Coletas e identificação botânica}

A coleta do material botânico e as observações 

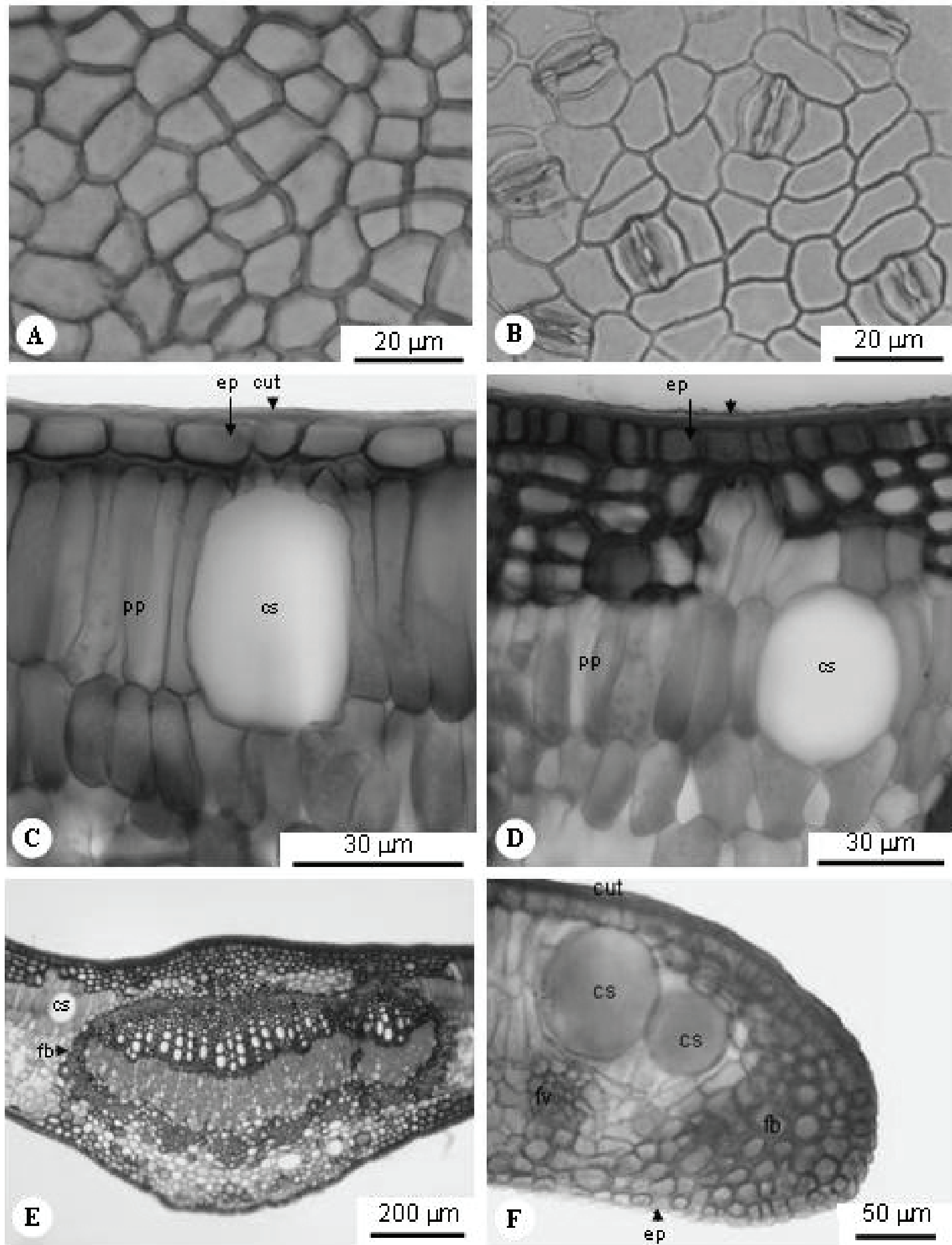

Figura 2. A. face adaxial da epiderme, vista frontal; B. face abaxial da epiderme com estômatos, Vista frontal; C. Secção transversal do mesofilo, evidenciando a epiderme (ep), o parênquima paliçádico (pp), e célula secretora (sc); D. Secção transversal ao nível da nervura principal, detalhe evidenciando a célula secretora; E. Seç̧ão transversal ao nível da nervura principal; F. Bordo da lâmina foliar em secção transversal. Legendas: epiderme com as paredes poligonais, retas, espessadas (ppr); estômatos (est); tricomas tectores, unicelulares (tt); célula secretora (cs); feixe vascular (fv); esclerídeos (esc); parênquima paliçádico (pp); fibras esclerenquimáticas (fe); parênquima esponjoso (pe). 
de campo foram realizadas nas proximidades da Lagoa do Paturi, no município de Santa Rita, no estado da Paraíba, Brasil, em março e abril de 2004. Uma parte do material foi fixada em FAA $_{50}$ por 48 horas e em seguida em álcool $70^{\circ}$. A outra parte foi herborizada, seguindo a metodologia descrita por Forman e Bridson (1989). O material coletado foi identificado após estudos morfológicos, cuja exsicata (Agra \& Góes, 6483) encontra-se depositada no Herbário Prof. Lauro Pires Xavier (JPB), com duplicatas na coleção de referência do Laboratório de Tecnologia Farmacêutica Prof. Delby Fernandes de Medeiros (LTF), ambos da Universidade Federal da Paraíba.

\section{Estudo morfológico}

Foram analisados caracteres da morfologia foliar relacionados à composição, filotaxia, tamanho, cor, consistência, contorno, ápice, base, margem, venação e superfície da lâmina foliar. Com relação ao pecíolo, foram observados os seguintes caracteres: aspecto geral, inserção na lâmina, tamanho, secção transversal e superfície (Vidal; Vidal 1995). As amostras foram analisadas e ilustradas com auxílio de estereomicroscópio binocular com câmera-clara, Zeiss.

\section{Estudo anatômico}

A descrição anatômica da espécie em estudo foi realizada em folhas adultas a partir de seções transversais nas áreas proximal, mediana e distal do pecíolo, e nas regiões de bordo, 1/3 mediano e na nervura central da lâmina foliar. Os cortes transversais foram efetuados à mão livre, com auxílio de lâmina cortante, utilizando-se isopor como suporte, posteriormente clarificados com hipoclorito de sódio $50 \%$, em seguida lavados em água destilada, corados com azul de astra e fucsina básica, montados entre lâmina e lamínula com glicerina 50\%, segundo técnica modificada de Kraus e Arduin (1997).

Para o estudo da epiderme e seus anexos, foram efetuadas seções paradérmicas, à mão livre, complementadas pela dissociação química. As seções foram realizadas nas duas superfícies da lâmina foliar. Para a dissociação química, fragmentos de $1 \mathrm{~cm}^{2}$ foram imersos em uma solução de ácido nítrico a $10 \%$, pelo período de $24 \mathrm{~h}$. Posteriormente, os fragmentos foram retirados e lavados em água destilada, com auxilio de um pincel, corados e montados entre lâmina e lamínula, com glicerina a 50\%. As descrições, ilustrações e fotomicrografias foram realizadas ao microscópio óptico Olympus CH30, com câmara fotográfica, Olympus PM-BP35. Para a classificação dos estômatos seguiu-se Metcalfe e Chalk (1979). A caracterização das paredes celulares, mesofilo e dos tricomas baseou-se em Fahn (1974).

Testes histoquímicos foram realizados em material recém coletado, para a determinação de cutina e óleo essenciais pelo Sudan III, e mucilagem pelo azul de metileno (Johansen, 1940, Costa, 1996).

\section{RESULTADOS}

Ocotea gardneri (Meisn.) Mez, Jahrb Konigl. Bot. Gart. Berlin. 5:338.1989.

Sinonímia. Mespilodaphne gardneri Meisn., in De Candolle, A. P. (ed.) Prodromus Systematis Naturalis Regni Vegetabilis 15(1): 99. 1864.

Descrição morfológica da folha. Lâmina foliar com 2,7-10,5 x 1,3-4,7 cm, consistência coriácea, contorno elíptico a oval-elíptico, ápice acuminado, base simétrica e arredondada, margem inteira, ondulada, discolor, verdeescuro, brilhante, com a venação levemente proeminente adaxial, verde claro, opaco, e fortemente proeminente abaxial. Pecíolo medindo 0,9-1,3 cm de comprimento, aplanado adaxial e convexo abaxial, levemente curvo, com projeções laterais na região apical, estriado (Figura 1).

Descrição anatômica. Em vista frontal, a epiderme da lâmina foliar, na face adaxial, apresenta células epidérmicas de formato poliédrico, tamanhos irregulares, paredes anticlinais retas e espessadas, com áreas translúcidas, que correspondem às células secretoras próximas à epiderme (Figura 2A). $\mathrm{Na}$ face abaxial, observam-se células epidérmicas semelhantes as da face adaxial, porém menores, com estômatos do tipo paracítico (Figura 2B).

Em secção transversal, a lâmina foliar apresenta epiderme uniestratificada, revestida por cutícula espessada, com células de formato quadrangular ou retangular na face adaxial, menores e tabulares na face abaxial. O mesofilo é do tipo isofacial ou heterogêneo simétrico, apresentado o parênquima paliçádico, próximo à epiderme adaxial, formado por 2 a 3 séries, sendo a primeira composta por células mais alongadas. Adjacente à face inferior, observa-se uma única série de células paliçádicas, menores. O parênquima lacunoso é constituído por 4-5 séries. Dispersas no mesofilo, observam-se células secretoras, de formato arredondado ou elíptico, sendo as células elípticas maiores e localizam-se, frequentemente, junto a face adaxial. Feixes vasculares colaterais são encontrados inseridos no mesofilo, envolvidos por uma bainha esclerenquimática (Figura 2C-D).

$\mathrm{O}$ bordo da lâmina foliar encontra-se levemente fletido e exibe a epiderme composta por células de tamanho e forma irregulares, revestida por cutícula bastante espessada. Adjacente à epiderme, observam-se células secretoras e 4-5 séries de esclerênquima (Figura 2F)

A nervura central, em secção transversal, apresenta formato biconvexo, com a epiderme uniestratificada, formada por células de diferentes tamanhos, revestida por cutícula espessada. Junto à epiderme, observa-se o colênquima anelar seguido do parênquima fundamental, onde são encontradas fibras 


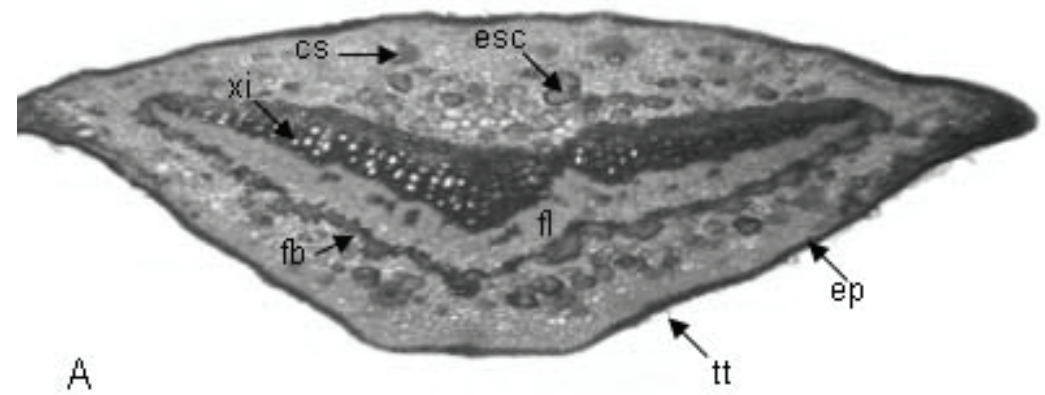

A
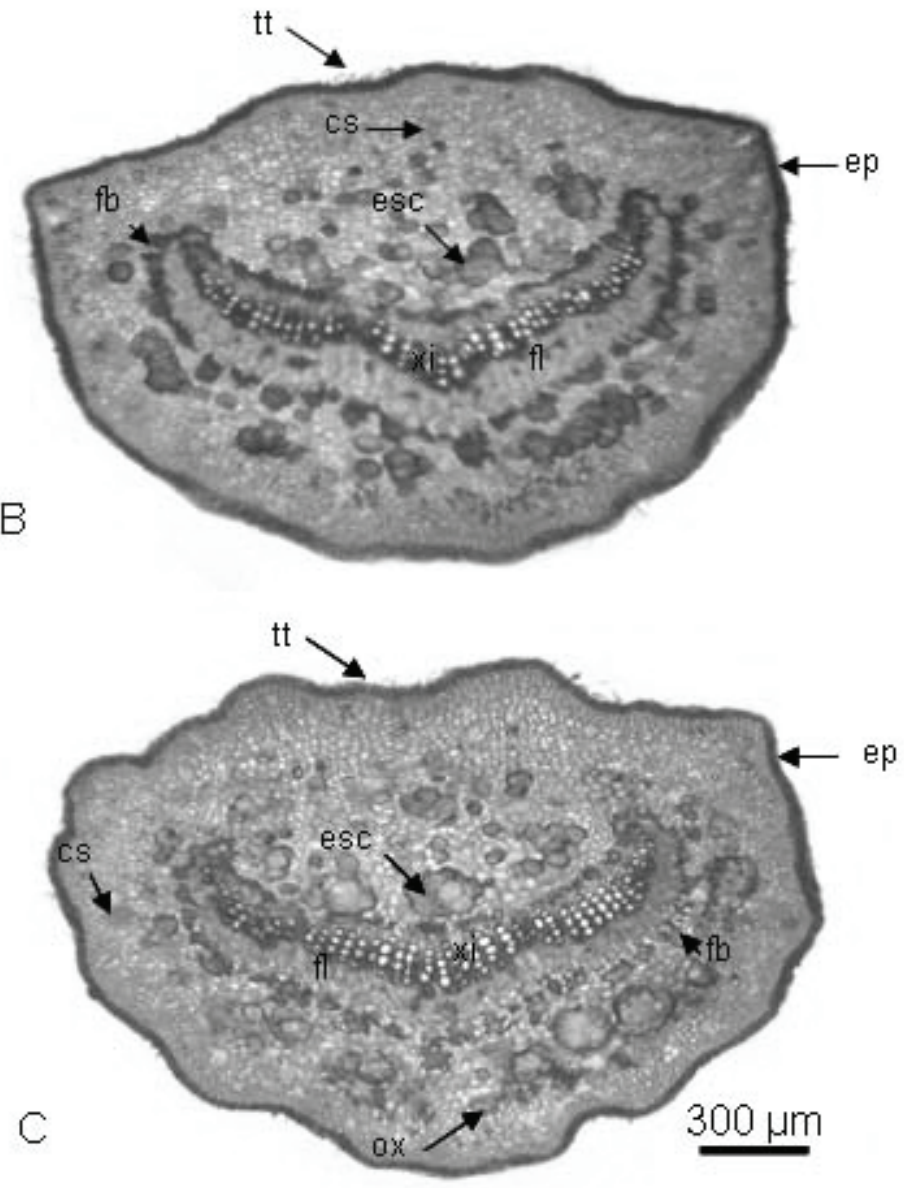

Figura 3. A-C. Secção transversal do pecíolo: A. região distal mostrando prolongamentos laterais; B. região mediana; C. região proximal. Legendas: ep - epiderme; xi xilema; $\mathrm{fl}$ - floema; $\mathrm{sc}$ - célula secretora; $\mathrm{tt}$ - tricoma; esc - esclerídeos; fb - fibras esclerenquimáticas.

esclerenquimáticas e algumas células secretoras. As fibras esclerenquimáticas podem estar isoladas ou agrupadas, sendo predominantes na face adaxial. Na região central, há um único feixe vascular do tipo colateral, praticamente reto e envolvido por uma densa bainha de fibras esclerenquimáticas (Figura 2E).

O pecíolo, em secção transversal, varia de plano-convexo na região distal a biconvexo nas regiões mediana e proximal, com dois prolongamentos laterais abaxial. O contorno é irregular, variando de largo-sulcado a ondeado, da região proximal para a distal. A epiderme é uniestratificada, revestida por cutícula espessada, com tricomas unicelulares, papilares frequentemente, curtos. A epiderme é ondulada, sendo que essa ondulação vai se acentuando na direção da região proximal. Adjacente à epiderme, encontram-se várias camadas de colênquima anelar, sendo o parênquima fundamental formado por células irregulares. Nesta região são encontrados vários grupamentos de esclereídeos e fibras esclerenquimáticas, principalmente isoladas, e células secretoras. Um único 
feixe vascular evidencia-se na região central, sendo este do tipo colateral e em forma de arco, nas três regiões. Uma bainha de fibras esclerenquimáticas circunda o feixe vascular, mais densa distalmente, que gradativamente se descontinua na direção proximal. Idioblastos em forma de ráfides de oxalato de cálcio são observados na região do floema (Figura 3A-C).

Testes histoquímicos evidenciaram as presença de óleo essencial e mucilagem nas células secretoras observadas.

\section{DISCUSSÃO}

A morfologia externa das folhas de Ootea gardneri está de acordo com a descrição de Barreto (1990), exceto pela presença freqüente de tricomas apenas nas axilas do primeiro par de nervuras secundárias, caráter não observado em Ootea gardneri.

Os resultados da anatomia foliar de Ootea gardneri revelaram um conjunto de caracteres distintos para esta espécie, que podem auxiliar em sua identificação. Dentre estes, destaca-se o mesofilo do tipo isobilateral, que não é usual na família Lauraceae, cujo parênquima paliçádico adjacente à epiderme abaxial é atípico, formado por células mais curtas que as dos estratos voltados para a epiderme adaxial. Pelo levantamento realizado na bibliografia especializada, este é o primeiro relato de mesofilo isobilateral em uma espécie de Lauraceae. Solereder (1908) e Metcalfe e Chalk (1972) descreveram o mesofilo de Lauraceae como sendo do tipo dorsiventral, trabalhos mais recentes como Marques (2001), que estudou cinco espécies desta família, também relatam o mesofilo com o padrão dorsiventral nas espécies estudadas.

As folhas hipoestomáticas, com estômatos do tipo paracítico, é um padrão característico da família Lauraceae, de acordo com Metcalfe e Chalk (1972), como também com os estudos de ontogenia realizados por Avita e Inandar (1981), que permitiram estabelecer que nesta família ocorre estômatos paracíticos.

A presença de tricomas simples, unicelulares e pluricelulares, é uma característica comum na família Lauraceae, de acordo com Fahn (1990), embora em O. gardneri tenha sido observado de tricomas simples, unicelulares, apenas no pecíolo, sendo a lâmina foliar glabra.

O. gardneri apresenta apenas um único feixe vascular na região central da nervura mediana e do pecíolo, que é do tipo colateral, circundado por uma bainha de esclerênquima, porém menos contínua na porção basal do pecíolo. Os feixes vasculares, ao longo do mesofilo, também são colaterais e têm bainha de fibras, entretanto, o esclerênquima não é um caráter relevante que auxilie na caracterização ou identificação de $O$. gardneri. De acordo com Metcalfe; Chalk (1972), esta bainha é um caráter comum a vários grupos taxonômicos, inclusive em Lauraceae.
A presença simultânea de células secretoras de óleos e mucilagens, observadas em O. gardneri, é uma característica comum em espécies de Lauraceae, de acordo com Metcalfe (1987) e Metcalfe; Chalk (1972), também relatada em trabalhos mais recentes como o de Marques (2001) para Ocotea. Com relação à morfologia destas células, o formato esférico a oblongo e o tamanho maior que as demais células do parênquima, observado em folhas de $O$. gardneri, estão de acordo com o tipo descrito por Paciornik (1996) para Lauraceae, portanto, não se constitui de um caráter relevante para a distinção de táxons no nível infra-familiar.

\section{CONCLUSÕES}

A análise morfo-anatômica de folhas de Ocotea gardneri permitiu a identificação do mesofilo do tipo isobilateral, como um caráter exclusivo para Ocotea gardneri, nunca referido para outra espécie de Ocotea ou mesmo para outro representante da família Lauraceae. Além disso, a presença de folhas hipoestomáticas, com estômatos do tipo paracítico, e células secretoras de óleos e mucilagens, aliados aos caracteres morfológicos são diagnósticos na identificação da espécie estudada, permitindo o estabelecimento de parâmetros que possibilitarão a caracterização de folhas de Ocotea gardneri em testes de autenticidade, bem como auxiliarão em estudos taxonômicos da espécie.

\section{AGRADECIMENTOS}

À Coordenação de Apefeiçoamento de Pessoal de Nível Superior (CAPES) e ao Conselho Nacional de Desenvolvimento Científico e Tecnológico (CNPq) pelas bolsas concedidas aos autores; Profa. Dr. Maria Nilce Sousa Ribeiro, Coordenadora do Programa de Qualificação Institucional (PQI-CAPES/UFMA/UFPB) e Prof. Dr. Isaac Medeiros, Diretor do Laboratório de Pesquisa Farmacêutica "Prof Delby Fernandes de Medeiros" pelo apoio institucional; Dr. Jnanabrata Bhattacharyya pela revisão do Abstract; Patrícia França Freitas pelas ilustrações; Dulce G. Oliveira pelo apoio técnico.

\section{REFERENCIAS}

Avita S, Inmadar JA 1981. Stomatal complex in Lauraceae structure and ontogeny. Acta Botanica Indica 9: 5056.

Barbosa-Filho JM, Vargas MRW, Silva IG, França IS, Morais LCSL, Cunha EVL, Silva MS, Souza MFV, Chaves COM, Almeida RN, Agra MF 1999. Ocotea duckei: exceptional source of yangambin and other furofuran lignans. An Acad Bras Cienc 71: 231-238.

Barreto RC 1990. O gênero Ocotea Aubl (Lauraceae) no estado de Pernambuco. XXXIV Congresso Nacional de Botânica. Brasília, Brasil. p.175-199.

Barroso GM, Guimarães EF, Ichaso CLF, Costa CG, Peixoto 
AL, 2002. Sistemática das angiospermas do Brasil. 2.ed. Viçosa: Editora UFV.

Bruni R, Medici A, Andreotti E, Fantin C, Muzzoli M, Dehesa M, Romagnoli C, Sacchetti G 2004. Chemical composition and biological activities of ishipingo essential oil, a traditional ecuadorian spice from Ocotea quixos (Lam.) Kosterm. (Lauraceae) flower calices. Food Chem 85: 415-421.

Budel JM, Farago PV 2004. Aspectos botânicos e químicos do gênero Ocotea Aublet, Lauraceae. Revista de Estudos Vale do Iguaçu 4:31-39.

Castiglioni JA 1951. Lauraceas Argentines I. Gênero Nectandra. Boletin de la Sociedad Argentina de Botânica 4: 6794

Costa, AF 1996. Farmacognosia. Lisboa: Calouste Gulbernkian v.3.

Dias CS, Silva IG, Cunha EVL, Silva MS, Braz-Filho R, Barbosa-Filho JM 2003. Isolamento e identificação de novos alcalóides de Ocotea duckei Vattimo (Lauraceae). Rev Bras Farmacogn 13(Supl. 1): 6263.

Dias KL, Silva C, Barbosa-Filho JM, Almeida RN, Azevedo NC de, Medeiros IA 2004. Cardiovascular effects induced by reticuline in normotensive rats. Planta Med 70: 328-333.

Fahn A 1990. Plant anatomy. 2. Great Britain: Pergamon Press.

Farago PV, Budel JM, Duarte MR, Nakashima T 2005. Análise morfoanatômica de folhas de Ocotea puberula (Rich.) Nees, Lauraceae. Rev Bras Farmacogn 15: 250-255.

Faria-Neto HC, Tibirica EV, Barbosa-Filho JM, Thomas G, Cordeiro RSB 1995a Yangambin, a new naturallyoccurring platelet activating factor receptor antagonist: binding and in vitro studies. Planta Med 61: 101-105.

Faria-Neto HC, Araujo CV, Moreira S, Bozza PT, Thomas G, Barbosa-Filho JM, Cordeiro RS, Tibirica EV 1995b. Yangambin, a new naturally-occuring platelet activating factor receptor antagonist: in vivo pharmacological studies. Planta Med 61: 106-112.

Forman L, Bridson D 1989. The herbarium handbook. Great Britanic: Royal Botanic Gardens, Kew.

Gutierrez MA, Oliveira F 1987-1989. Caracterização farmacognóstica da droga e do extrato flúido de Persea americana Miller. Rev Bras Farmacogn 2-4: 29-44.

Johansen DA 1940. Plant microtechnique. New York: Mc Graw Hill Book

Kraus JE, Arduin M 1997. Manual básico de métodos de morfologia vegetal. Rio de Janeiro: EDUR.

Marques CA 2001. Anatomia foliar aplicada à taxonomia de espécies de Lauraceae Lind. Viçosa, 75p. Dissertação de Mestrado - Programa de Pós-Graduação em Botânica, Universidade Federal de Viçosa.

Metcalfe CR, Chalk L 1979. Anatomy of the Dicotyledon. Oxford: Claredon Press. v.1

Metcalfe CR 1987. Anatomy of the dicotyledons: Magnoliales, Illiciales and Laurales. Oxford: Clarendo Press.

Metcalfe CR, Chalk L 1972. Anatomy of the Dicotyledones: leaves, stem and wood in relation to taxonomy with notes on economic uses. Oxford: Clarendon Press, v.2.

Morais LCSL, Barbosa-Filho JM, Almeida RN 1998. Central depressant effects of reticuline extracted from Ocotea duckei in rats and mice. $J$ Ethnopharmacol 62: 57-61.
Oliveira CW, Callado CH, Marquete O 2001. Anatomia do lenho de espécies do gênero Nectandra Rol. Ex Rottb. (Lauraceae). Rodriguesia 52: 125-134.

Parciornik EF 1996. Tendências evolutivas em Lauraceae Juss. Rio de Janeiro, 137p. Tese de Doutorado Departamento de Genética, Universidade Federal do Rio de Janeiro.

Ribeiro RA, Carmo LG, Vladimorova I, Jurkiewicz NH, Jurkiewicz A 2003. Nantenine blocks muscle contraction and $\mathrm{Ca} 2+$ transient induced by noradrenaline and $\mathrm{K}+$ in rat vas deferens. Eur $J$ Pharmacol 470: 37-43.

Rohwer JG 1986. Prodromous einer monographie der Gattung Aublet (Lauraceae), sensu lato. Mitt Allg Bot Hamburg 20: 3-278.

Rohwer JG 1993. Lauraceae. In Kubitzki K, Rohwer JG, Bittrich (org.) The families and genera of vascular plants. Berlin:Springer-Verlag, p.366-391.

Santos M, Oliveira PL 1988. Aspectos anatômicos da lâmina foliar de Ocotea porosa (Nees et MArt. Ex Nees) J. Angely (Lauraceae). Insula 18: 3-22

Santos M, Oliveira PL 1995. Aspectos anatômicos do pecíolo de quatro espécies do gênero Ocotea Aubl. (Lauraceae) ocorrentes no Rio Grande do Sul. Insula 24: 3-14.

Serra MF, Diaz BL, Barreto EO, Pereira APB, Lima MCR, Barbosa-Filho JM, Cordeiro RSB, Martins MA, Silva PMR 1997. Anti-allergic proprperties of natural PAF antagonist yangambin. Planta Med 63: 207-212.

Solereder H 1908. Systematic anatomy of the dicotyledons: a handbook for laboratories of purê and applied botany. Oxford: Claredon Press.

Souza LA, Moscheta IS 2000. Morfo-anatomia do desenvolvimento do fruto de Ocotea puberula (Rich.) Nees e de Nectandra megapotamica (Spreng.) Mez (Lauraceae). Acta Cientifica Venezolana 51: 84-89.

Souza GC, Haas APS, Von Poser GL, Schapoval EES, Elisabetsky E 2004. Ethnopharmacological studies of antimicrobial remedies in the south of Brazil. $J$ Ethnopharmacol 90: 135-143.

Van der Werff H 1991. A key to the genera of Lauraceae in the New World. Ann Missouri Bot Garg 78: 377-387.

Van der Werff H 2002. A synopsis of Ocotea (Lauraceae) in Central America and Southern Mexico. Ann Missouri Bot Garg 89: 429-451.

Vidal WN, Vidal MRR 1995. Botânica organografia. Viçosa: Imprensa Universitária UFV.

Zschocke S, Drewes SE, Paulus K, Bauer R, Van Standen J 2000a. Analytical and pharmacological investigation of Ocotea bullata (black stinkwood) bark and leaves. J Ethnopharmacol 71: 219-230.

Zschocke S, Van Standen J, Paulus K, Bauer R, Horn MM, Munro NJ, Drewes S 2000b. Stereostructure and anti-inflamatory activity of three diasteromers of ocobullenone from Ocotea. Phytochemistry 54: 591595 